\title{
Effect of Statroltea on lipid metabolism in rats fed on high-fat diet
}

\author{
Feumba Dibanda Romelle ${ }^{1,2}$, Oben Julius Eyong ${ }^{3}$, Mbofung Carl Moses ${ }^{1,4}$ \\ ${ }^{1}$ Food and Nutrition Research Centre, IMPM, Yaounde, Cameroon \\ ${ }^{2}$ Department of Food Sciences and Nutrition, ENSAI, University of Ngaoundere, Cameroon \\ ${ }^{3}$ Department of Biochemistry, Faculty of Sciences, University of Yaounde I, Cameroon \\ ${ }^{4}$ College of technology, University of Bamenda, Cameroon
}

\section{Email address:}

feumbaromelle@yahoo.fr (F. D. Romelle)

\section{To cite this article:}

Feumba Dibanda Romelle, Oben Julius Eyong, Mbofung Carl Moses. Effect of Statroltea on Lipid Metabolism in Rats Fed on High-Fat Diet. Journal of Food and Nutrition Sciences. Vol. 2, No. 4, 2014, pp. 99-104. doi: 10.11648/j.jfns.20140204.11

\begin{abstract}
The present study was undertaken to evaluate the anti-obesity potential of a phenolic- rich herbal tea beverage produced in northern regions of Cameroon from the leaves of Stathmostelma sp. (Statroltea). The effect of Statroltea (5 $\mathrm{mg} / \mathrm{Kg} /$ day) on lipid metabolism was assayed in male rats fed on either standard or high-fat diet for 60 days. Rats of both diet fed Statroltea presented significant $(\mathrm{P}<0.05)$ reduced body weight than their controls with a rate of reduction varying from 5 to $15 \%$. The consumption of Statroltea for 60 days significantly lowered abdominal fat index, blood total and LDL cholesterol, triglycerides and hepatic lipids $(\mathrm{P}<0.05)$. Fecal lipids were found to be more excreted in all Statroltea fed rats. This is the first report on the effect of Stathmostelma $s p$. leaves on lipid metabolism and the study demonstrates that Statroltea, an herbal tea from Stathmostelma sp. leaves has a potential as anti-obesity functional food beverage.
\end{abstract}

Keywords: Obesity, Lipid Metabolism, Statroltea, Herbal Tea, Functional Food Beverage

\section{Introduction}

Obesity is a medical condition characterized by an excessive accumulation of fat in the body [1]. About 1.2 billion people worldwide are overweight and at least 300 million of them are obese with World Health Organization projecting that more than 700 million adults worldwide will be obese by 2015 [2]. Obesity is strongly associated with metabolic syndrome which is characterized by the presence of insulin resistance, hypertension, and hyperlipidemia [3]. Therefore, prevention and treatment of obesity are important for achieving a healthy life [1]. Owing to the adverse side effects associated with many antiobesity drugs, more recent trials have focused on screening herbal sources that have been reported to reduce body weight with minimal side effects [3].

Many teas (green tea, mate tea, etc.) have been widely used all over the world for weight reduction purpose $[4,5]$. Their putative effects have been attributed to phenolic compounds which are reported to inhibit in vitro activity of pancreatic lipase, a key enzyme involved in the digestion of dietary lipids [6].

A phenolic- rich herbal tea beverage obtained from the leaves of Stathmostelma sp. (Statroltea) is produced in the northern regions of Cameroon. Feumba et al. [7] reported that Statroltea inhibits in vitro pancreatic lipase activity. However, no work has been reported on its in vivo activities. It is against this background that the study aims to investigate the in vivo anti-obesity potential of Statroltea.

\section{Material and Methods}

\subsection{Production of Statroltea}

The fresh leaves of Stathmostelma sp. were harvested in Ngaoundere, Cameroon and identified at the Cameroonian National Herbarium (Voucher $\mathrm{N}^{\circ}$ 59014). Leaves were roasted at $144^{\circ} \mathrm{C}$ for $20 \mathrm{~min}$ and cooled to room temperature. Roasted leaves were ground and bagged in 3 grams. Bags containing $3 \mathrm{~g}$ of roasted leaves were brewed for $23 \mathrm{~min}$ in $300 \mathrm{~mL}$ of preheated water at $60^{\circ} \mathrm{C}$ to give an infusion called in this study Statroltea. Statroltea was dried at $40^{\circ} \mathrm{C}$ to obtain a dry residue that was used in the study. The composition of Statroltea expressed in percentage of total soluble solids (TSS) is recorded in Table 1. 


\subsection{Effect of Statroltea on Lipid Profile of Rats}

\subsubsection{Experimental Animals}

Male Wistar rats, aged 3-4months, weighing 250-350g, were purchased from the animal house of the Laboratory of Animal Physiology, Faculty of Sciences of the University of Ngaoundere, Cameroon. Animals were maintained in standard laboratory conditions $\left(23 \pm 2^{\circ} \mathrm{C}, 12 \mathrm{~h}\right.$ photoperiod) having free access to tap water and food. Procedures used in the study were approved by the Animal Ethics Committee of the Ngaoundere University. Rats were weighed and examined for physical abnormalities a day before initiation of test.

\subsubsection{Diet Administration}

The experimentation was conducted during 60 days. Animals were fed either with high-fat diet (10 rats) or with standard diet (10 rats). The standard and the high-fat diets were formulated as reported in Table 2 . For each diet, rats housed individually received distilled water ( 5 control rats) while treated groups ( 5 animals) received Statroltea at the dose of $5 \mathrm{mg} / \mathrm{kg}$.

\subsubsection{Statroltea Administration}

Statroltea was administrated daily for 60 days. A mass of Staroltea $(1.25-1.75 \mathrm{mg})$ corresponding to the dose of $5 \mathrm{mg} / \mathrm{Kg}$ of body weight was dissolved in $5 \mathrm{~mL}$ of distilled water. The tea solution was mixed with $3 \mathrm{~g}$ of appropriate meal and the tea treated-meal was given to each animal.

Table 1. Basic proximate and phenolic composition of Statroltea

\begin{tabular}{lc}
\hline Nutrients & (mg\% TSS) \\
\hline Total free sugars & $349.68 \pm 6.09$ \\
Reducing free sugars & $330.57 \pm 5.56$ \\
Crude proteins & $666.87 \pm 21.09$ \\
Phenolic compounds & (mg\% TSS) \\
Total Phenolics & $97.64 \pm 1.35$ \\
Total flavonoids & $68.10 \pm 3.59$ \\
Total tannins & $16.17 \pm 0.41$ \\
\hline
\end{tabular}

Values represent mean $\pm \mathrm{SD}$ of 3 replicates; Total phenolics were expressed as mg gallic acid equivalents \% TSS; total flavonoids were expressed as mg quercetin equivalents \% TSS; Total tannins were expressed as tannic acid equivalents \% TSS; Total free sugars and reducing free sugars were expressed as fructose equivalents \% TSS; Crude proteins were expressed as $\mathrm{N} \times 6.25$

Table 2. Composition of standard and high-fat diets

\begin{tabular}{lll}
\hline Ingredients (\%) & Standard diet & High-fat diet \\
\hline Cassava starch & 69.5 & 39.5 \\
Casein & 21.0 & 21.0 \\
Soy bean oil & 5.0 & 5.0 \\
Palm oil & 0.0 & 30.0 \\
Vitamin mix & 1.0 & 1.0 \\
Mineral mix & 3.5 & 3.5 \\
\hline
\end{tabular}

Rats were given ad libitum portion of untreated standard or high-fat meal after they have completely eaten the teatreated meal.

\subsubsection{Measurement of Food Intake and Variation in Body Weight}

The food intake of all animals was assessed daily and the body weights of rats were recorded every ten days after which variations in body weights were calculated.

\subsubsection{Measurement of Blood Lipids}

At the end of the treatment, animals were fasted overnight and anesthetized with chloroform and blood collection from the jugular vein. Blood samples were collected into heparinized centrifuge tubes. The level of total cholesterol, triglycerides, and HDL-cholesterol were measured using commercial enzymatic kits (Spinreact, Spain) and the LDL-cholesterol concentration in the plasma was calculated using the equation described by Friedewald et al. [8].

\subsubsection{Measurement of Abdominal Fat Index, Hepatic and Fecal Lipids}

At the end of the experimental period, abdominal fat and liver were excised, washed in $\mathrm{NaCl}(0.9 \%)$ and weighed. The abdominal fat index was represented by the ratio abdominal fat/body weight. Feces collected every ten days during the course of the experiment were dried in an oven at $50^{\circ} \mathrm{C}$, ground and homogenised. To determine hepatic or faecal lipid content, a sample of ground liver or feces was extracted in $5 \mathrm{~mL}$ of the mixture of chloroform: methanol $(2: 1 \mathrm{v} / \mathrm{v})$, using the method described by Folch et al. [9].

\subsection{Statistical Analysis}

Statistical analysis was performed for all parameters. One-way analysis of variance (ANOVA) was used to determine statistical difference between control and treated groups with $\mathrm{P}$ values less than 0.05 considered as significant.

\section{Results and Discussion}

\subsection{Effect of Statroltea on Body Weight}

The ingestion of high-fat diet resulted in gradual increase in body weight with time whereas there was no significant change in body weight in those fed on the standard diet (Fig. 1). This result is in accordance with that of Amin and Nagy [10] who reported that feeding rats on high fat diet significantly increased their body weight. The consumption of Statroltea has brought the variation in body weight from a positive to a negative rate with a percentage of reduction situated between 5 to $15 \%$. According to Grundy et al. [11], it has been recommended that weight reduction programs should focus on achieving a modest weight loss of $7-10 \%$ of the initial weight. Statroltea can therefore be used in weight reduction programs. This reductive effect in body weight of rats by Statroltea is irrespective of the type of diet because the ingestion of Statroltea did produced weight losses in all the Statroltea-treated groups irrespective of the diet consumed with these weight losses occuring from the 
beginning of the ingestion of Statroltea.

Similarly, Sogawa et al. [12] found that low energy diet containing $3 \%$ of green tea or $3 \%$ tokushima tea produced significant weight loss in male rats. In the same light, Hala et al. [13] reported that $5 \mathrm{~mL}$ of green tea extract prepared freshly and given three times daily to a high fat fed male rats produced a significant decrease in their body weight gain. Kao et al. [14] also reported that purified EGCG (50$100 \mathrm{mg} / \mathrm{kg}$ ), a green tea catechin, significantly reduced or prevented an increase in the body weight of lean and obese Zucker rats with the weight losses attributed to food intake reduction.

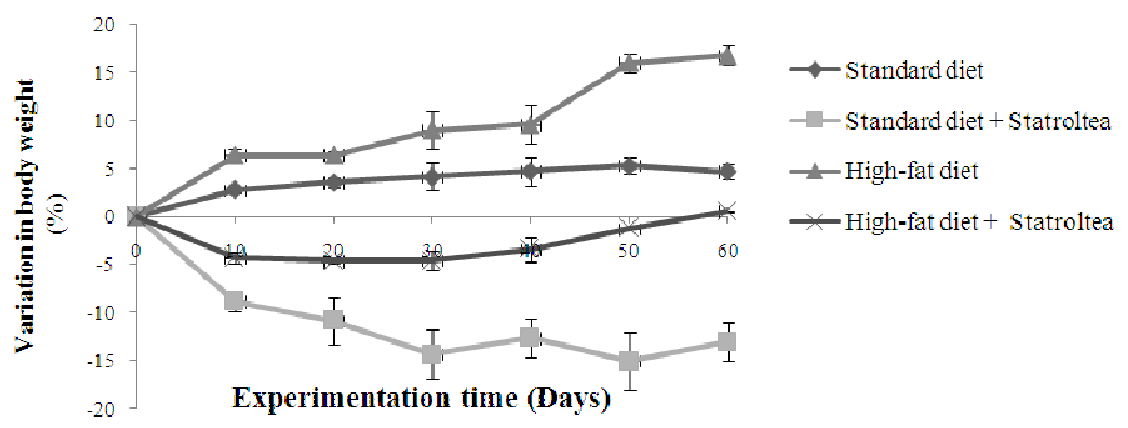

Figure 1. Variation in the body weight of male rats fed standard or high-fat diet with or without Statroltea

\subsection{Effect of Statroltea on Food Intake and Abdominal Fat Index}

Food intake is regulated by a variety of endocrine parameters (leptin, neuropeptides, glucagon, etc.) which are influenced by peripheral factors and by central neuroendocrine systems [15]. From Table 3, it is noticeable that Statroltea produced an increase in the food consumption of rats fed with the standard diet or the highfat diet. Statroltea may influence any components involved in food intake. On the other hand, Bajerska et al. [16] found that the administration of $1.1 \%$ and $2.2 \%$ of green tea aqueous extract to high- fat diet fed rats produced no change in their food intake. In normal fed diet rats, Nakamura et al. [17] reported no change in food intake when green tea polyphenol $(0.01,0.05,0.1,0.2,0.5$ and 1.0 $\mathrm{g} / \mathrm{kg}$ ) are consumed.

The body fat index (Table 3) depicts that final parametrial adipose tissue weight was significantly increased by feeding high-fat diet to male rats compared to their controls $(\mathrm{P}<0.05)$. Statroltea produced a relative reduction of $15.88 \%$ of this abdominal fat accumulation in male rats. This reduction of body fat index produced by Statroltea is concomitant with several reports on effects of traditional Camellia sinensis tea components on body fat accumulation.

Table 3. Effect of Statroltea on food consumption and abdominal fat index of rats

\begin{tabular}{llll}
\hline Diet & Groups & $\begin{array}{l}\text { Food consumption } \\
\text { (mg/g BW/day) }\end{array}$ & $\begin{array}{l}\text { Abdominal fat } \\
\text { index }(\mathbf{m g} / \mathbf{g ~ B W})\end{array}$ \\
\hline Standard & Control & $186.79 \pm 15.55$ & $19.46 \pm 1.27$ \\
diet & Statroltea & $290.08 \pm 50.00^{\mathrm{b}}$ & $20.54 \pm 1.30$ \\
High- fat & Control & $174.82 \pm 3.66$ & $43.46 \pm 3.63^{\mathrm{a}}$ \\
diet & Statroltea & $284.10 \pm 5.82^{\mathrm{b}}$ & $35.69 \pm 2.75^{\mathrm{b}}$ \\
\hline
\end{tabular}

a. Value significantly different from the control of the standard diet group $(\mathrm{P}<0.05)$

b. Value significantly different from the control within the same diet group $(\mathrm{P}<0.05)$

Table 4. Effect of Statroltea on blood lipids of male rats

\begin{tabular}{|c|c|c|c|c|}
\hline \multirow{2}{*}{ Blood lipids } & \multicolumn{2}{|l|}{ Standard diet } & \multicolumn{2}{|l|}{ High-fat diet } \\
\hline & Control & Statroltea & Control & Statroltea \\
\hline Total cholesterol (mg/ dL) & $76.10 \pm 1.13$ & $\begin{array}{l}58.48 \pm 1.88^{\mathrm{b}} \\
(21.87 \%)\end{array}$ & $83.04 \pm 3.40^{\mathrm{a}}$ & $\begin{array}{l}45.93 \pm 7.71^{b} \\
(37.30 \%)\end{array}$ \\
\hline Triglycerides (mg/ dL) & $135.12 \pm 2.50$ & $\begin{array}{l}123.47 \pm 4.16^{b} \\
(5.71 \%)\end{array}$ & $140.54 \pm 10.09$ & $\begin{array}{l}114.12 \pm 3.33^{\mathrm{b}} \\
(18.80 \%)\end{array}$ \\
\hline HDL- cholesterol (mg/ dL) & $27.09 \pm 2.37$ & $23.66 \pm 2.16$ & $24.12 \pm 3.28$ & $22.90 \pm 7.02$ \\
\hline LDL- cholesterol (mg/ dL) & $16.93 \pm 1.22$ & $\begin{array}{l}9.52 \pm 1.10^{b} \\
(43.77 \%)\end{array}$ & $33.81 \pm 7.76^{\mathrm{a}}$ & $\begin{array}{l}12.84 \pm 3.17^{b} \\
(55.18 \%)\end{array}$ \\
\hline Atherogenic Index (1) & $2.93 \pm 0.48$ & $\begin{array}{l}2.28 \pm 0.10^{\mathrm{b}} \\
(19.06 \%)\end{array}$ & $4.05 \pm 0.89^{\mathrm{a}}$ & $\begin{array}{l}2.01 \pm 0.11^{\mathrm{b}} \\
(49.97 \%)\end{array}$ \\
\hline Atherogenic Index (2) & $0.76 \pm 0.13$ & $\begin{array}{l}0.41 \pm 0.08^{b} \\
(45.86 \%)\end{array}$ & $1.56 \pm 0.21^{\mathrm{a}}$ & $\begin{array}{l}0.60 \pm 0.17^{\mathrm{b}} \\
(59.53 \%)\end{array}$ \\
\hline
\end{tabular}

a .Value significantly different from the control of the standard diet group $(\mathrm{P}<0.05)$

b. Value significantly different from the control within the same diet group $(P<0.05)$

Han et al. [4] found that the parametrial adipose weight significantly decreased from 2.08 to 1.04 after adding $0.5 \%$ Thea sinensis saponins to the high-fat diet for 11 weeks.
Ikeda et al. [18] observed a relative decrease of $21.85 \%$ in adipose tissue weight or visceral fat deposition after administration of $1 \%$ tea catechins for 23 days to rats. 
According to Tokimitsu [19], long term ingestion of tea catechins stopped accumulation of body fat in mice with high-fat diet induced obesity. However this effect was also found in non obese rats and was probably due to the activation of hepatic lipid metabolism [20].

\subsection{Effect of Statroltea on Blood Lipids}

The effects of Statroltea on blood lipids profile are recorded in Table 4.

It can be observed that consuming a high fat diet resulted in an increase in total cholesterol and LDL cholesterol in rats compared to rats fed on standard diet. This observation is in agreement with Woo et al. [21] who stated that in animal models of high fat diets, dramatic increases in serum total cholesterol and LDL- cholesterol but relatively slight changes in HDL- cholesterol were observed. The role of Statroltea in countering lipemic aberrations accompanying diet- induced hyperlipidemia was investigated and recorded in Table 4. The consumption of Statroltea for 60days significantly lowered both total and LDL cholesterol $(\mathrm{P}<0.05)$ and the relative reduction rates in all the Statroltea- treated groups were respectively above 20 and $40 \%$. Similarly, Zdunczyk et al. [22] stated that an extract of catechin from green tea was found to decrease the total cholesterol and LDL-fraction. By reducing total cholesterol and LDL cholesterol, Statroltea would reduce the incidence of coronary events [23].

Atherogenic index indicates the deposition of foam cells or plaque or fatty infiltration or lipids in heart, coronaries, aorta, liver and kidneys. It was observed that, the higher the atherogenic index was, the higher the risk of oxidative damage of the above organs. Table 4 shows that the consumption of a high-fat diet significantly increased atherogenic indexes exposing high-fat fed animals to more elevated risk of metabolic diseases. Statroltea ingestion significantly reduced atherogenic indexes for both $\operatorname{diet}(\mathrm{P}<$ 0.05). Ramadan et al. [24] reported that black tea and green tea extracts given at concentrations of 50 and $100 \mathrm{mg} / \mathrm{Kg}$ to male rats significantly reduced in dose dependant manner atherogenic indexes in obese groups but brought no significant change in standard diet fed rats. It is worthy to mention that the reduction of atherogenic indexes by Statroltea was relatively more marked in high-fat fed groups than in standard fed groups.

On the other hand, the concentration of HDL cholesterol in all the groups was not affected by Statroltea. This effect may be due to regularity in the activity of lecithin: cholesterol acyl transferase (LCAT), which may contribute to the regulation of blood lipids. LCAT plays a key role in incorporating free cholesterol into $\mathrm{HDL}$ and transfering back to VLDL or IDL, which is taken back by the liver cells [25].

Table 4 also revealed significant reduction in triglyceride levels in all the Statroltea fed rats. This effect may be related to the inhibition of enzymes responsible of fat metabolism (pancreatic lipase, lipoprotein lipase, and glycerophosphate dehydrogenase) since polyphenols from herbal sources have been reported to inhibit these enzymes $[26,27]$. These observations were consistent with Uchimaya et al. [28] who found that total plasma cholesterol and triglyceride levels in mice fed a standard diet containing 5\% black tea polyphenol extracts were respectively reduced to $79 \%$ and $67.5 \%$. Controversially, Murase et al. [29] reported that high-fat diet supplemented for 11 months with green tea catechins up to $0.5 \%$ produced a significant decrease in total cholesterol but did not alter plasma triglyceride in mice.

In the same line, De Vos and De Schrijver [30] found that the consumption of black tea by rats significantly lowered esterified and total cholesterol concentrations in plasma, while contents of free cholesterol and triglycerides were not influenced. The difference observed between the effect of Statroltea and that of green or black tea may be due to the amount of tea ingested, their content and composition in polyphenols. It can also be due to their content and composition in others bioactive compounds beside polyphenols which may act synergistically to influence lipid metabolism.

\subsection{Effect of Statroltea on Liver Lipids}

The behaviour of liver lipids after ingestion of Staroltea is displayed in Table 5. A high-fat diet may induce hepatic triglycerides accumulation, owing to the import of excess amounts of fatty acids into the liver. The excess fatty acids are then esterified and stored as triglycerides [31]. It can be observed that the deposition of lipids in the liver is reduced by the consumption of Statroltea administrated at $5 \mathrm{mg} / \mathrm{Kg}$ irrespectively of the type of $\operatorname{diet}(\mathrm{P}>0.05)$. This is consistent with Uchiyama et al. [28] who reported that giving normal or high-fat diet supplemented with black tea polyphenols to rats did not decrease liver total lipids until the supplemented concentration reached $5 \%$. In the same light, Nakamura et al. [17] stated that feeding animals with green tea polyphenols from 0.01 to $0.2 \mathrm{~g} / \mathrm{Kg}$ produced no significant changes in hepatic lipids parameters (total cholesterol, triglycerides, phospholipids), but higher concentrations $(0.5$ to $1.0 \mathrm{~g} / \mathrm{Kg})$ provoked a decrease in hepatic triglycerides. This decrease in hepatic triglyceride is possibly due according to Kobayashi-Hattori et al. [32] to an increased hepatic- $\beta$ oxidation activity.

\subsection{Effect of Statroltea on Fecal Lipids}

Fig. 2 displays the lipids excretion during the study. It can be observed that the pattern of fecal lipid excretion did not differ with the diet under study. For both diet, Statroltea ingestion increased significantly $(\mathrm{P}<0.05)$ the amount of excreted fecal lipids. This is concomitant of Uchiyama et al [28] who reported that fecal excretion in female mice fed a high fat diet containing 5\% black tea polyphenols extract increased 1.7- fold compared to mice only fed a high fat diet. In the same light, Hsu et al. [33] found that lipid excretion into feces was significantly higher in the polyphenol-enriched oolong tea period (12.9 - 19.3g/ 3 
days) than in the placebo period $(7.3-9.4 \mathrm{~g} / 3$ days $)$.

Table 5. Effect of Statroltea on liver lipids of rats

\begin{tabular}{lllll}
\hline \multirow{2}{*}{ Liver lipids } & \multicolumn{2}{c}{ Standard diet } & \multicolumn{2}{c}{ High- fat diet } \\
\cline { 2 - 5 } & Control & Statroltea & Control & Statroltea \\
\hline Total lipids (mg/g of tissue) & $74.16 \pm 3.20$ & $61.74 \pm 0.09^{\mathrm{b}}$ & $82.53 \pm 5.28$ & $75.26 \pm 6.16^{\mathrm{b}}$ \\
Triglycerides (mg/g of tissue) & $1.29 \pm 0.06$ & $1.08 \pm 0.10^{\mathrm{b}}$ & $1.83 \pm 0.06^{\mathrm{a}}$ & $0.33 \pm 0.05^{\mathrm{b}}$ \\
Total cholesterol (mg/g of tissue) & $0.89 \pm 0.06$ & $0.75 \pm 0.03^{\mathrm{b}}$ & $1.57 \pm 0.06^{\mathrm{a}}$ & $0.12 \pm 0.03^{\mathrm{b}}$ \\
\hline
\end{tabular}

a. Value significantly different from the control of the standard diet group $(\mathrm{P}<0.05)$

b. Value significantly different from the control within the same diet group $(\mathrm{P}<0.05)$

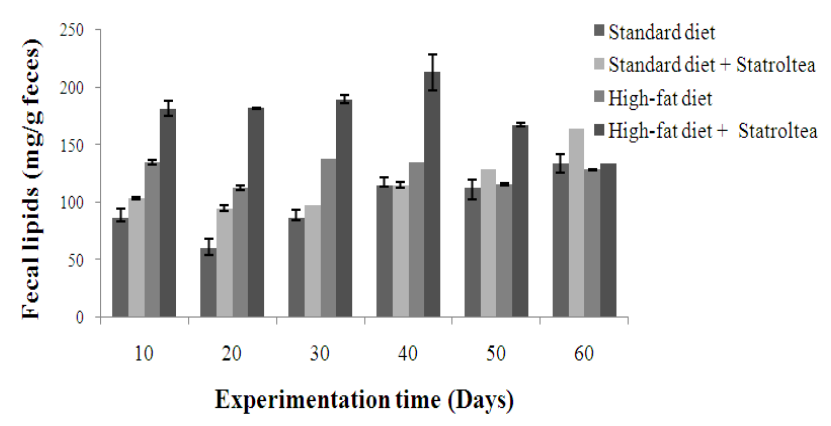

Figure 2. Effect of Statroltea on fecal lipids excretion of rats fed standard or high-fat diet

\section{Conclusion}

The present study demonstrates that the herbal tea beverage from Stathmostelma $s p$. regulates lipid metabolism and has a potential in the prevention of high-fat diet-induced obesity. The related effects are significant reduction of body weight, abdominal fat index, blood total cholesterol, LDL-cholesterol, triglycerides, hepatic lipids and significant increase in fecal lipids. This is the first report on the in vivo effect of Statroltea and the study demonstrates that Statroltea has a potentiality as antiobesity herbal tea. Further studies are necessary to determine the mechanism of action of Statroltea on all enzymes implicated in the lipid metabolism and to ascertain its safety.

\section{References}

[1] G. Kopelman, "Obesity as a medical problem," Nature, vol. 404, 2000, pp. 635-643.

[2] WHO Global strategy on diet, physical activity and health. World Health Report Geneva (2004).

[3] E. Kishino, T. Ito, K. Fujita and Y. Kiuchi, "A mixture of the Salacia reticulata (Kotala himbutu) aqueous extract and cyclodextrin reduces the accumulation of visceral fat mass in mice and rats with high-fat diet-induced obesity," Journal of Nutrition, vol. 136, 2006, pp. 433-439.

[4] L.-K. Han, Y. Kimura, M. Kawashima, T. Takaku, T. Taniyama, T. Hayashi, Y.-N. Zheng and H. Okuda, "Antiobesity effects in rodents of dietary teasaponin, a lipase inhibitor," International Journal of Obesity, vol. 25, 2001, pp. 1459-1464.
[5] F. Martins, T. M. Noso, V. B. Porto, A. Curiel, A. Gambero, D. H. M. Bastos, M. L. Ribeiro and P. O. Carvalho, "Maté Tea Inhibits In Vitro Pancreatic Lipase activity and Has Hypolipidemic Effect on High-fat Diet-induced Obese Mice", Obesity, vol. 18, 2010, pp. 42-47.

[6] S. I. Koo and S. K. Noh, "Green tea as inhibitor of the intestinal absorption of lipids: potential mechanism for its lipid-lowering effect," Journal of Nutritional Biochemistry, vol. 18,2007 , pp. 179- 183.

[7] D. R. Feumba, E. G. F. Ngando, J. E. Oben and C. M. F. Mbofung, "A Phenolic-Rich Herbal Tea from Stathmostelma $s p$. (Statroltea) Inhibits In Vitro Pancreatic Lipase Activity," Journal of Enzyme Research, vol. 4, 2013, pp. 50-53.

[8] W. T. Friedewald, R. I. Levy and D. S. Fredrickson, "Estimation of the concentration of low-density lipoprotein cholesterol in plasma, without use of the preparative ultracentrifuge," Clinical Chemistry, vol.18, 1972, pp. 499502.

[9] J. Folch, M. Lees and G. H. Sloane-Stanley, "A simple method for the isolation and purification of total lipids from animal tissues," Journal of Biological Chemistry, vol. 226, 1957, pp. 497 - 509.

[10] K. A. Amin and M. A. Nagy, "Effect of Carnitine and herbal mixture extract on obesity induced by high fat diet in rats," Diabetology \& Metabolic Syndrome, vol. 1, 2009, pp. 1-14.

[11] S. M. Grundy, J. I. Cleeman, S. R. Daniels, K. A. Donato, R. H. Eckel, B. A. Franklin, "Diagnosis and management of the metabolic syndrome: an American Heart Association/National Heart, Lung, and Blood Institute Scientific Statement," Circulation, vol. 112, 2005, pp. 27352752.

[12] M. Sogawa, T. Seura, S. Kohno, K. Hirasaka, Y. Yamaguchi, R. Takagaki, A. Harada, Y. Okumura, S. Yamamoto, K. Kishi and T. Nikawa, “ Awa (Tokushima) lactate-fermented tea as well as green tea enhance the effect of diet restriction on obesity in rats," The Journal of Medical Investigation, vol. 56, 2009, pp. 42-48.

[13] Hala, E. M. El-Kewawy, Farida, A. Al-Firdous and R. M. Nagib, "Beneficial effects of some beverage consumption and Orlistat drug on Diet Induced Obesity in Experimental Rate," Life Science Journal, vol. 8, 2011, pp. 667-675.

[14] Y. -H. Kao, R. A., Hiipakka and S. Liao, "Modulation of obesity by a green tea catechin," American Journal of Clinical Nutrition, vol. 72, 2000, pp. $1232-1234$.

[15] Y. -H. Kao, R. A., Hiipakka and S. Liao, "Modulation of Endocrine Systems and Food Intake by Green Tea Epigallocatechin Gallate,” Endocrinology, vol. 141, 2000, pp. 980-987. 
[16] J. Bajerska, M. Wozniewicz, J. Jeszka, S. Drzymala-Czyz and J. Walkowiak, "Green tea aqueous extract reduces visceral fat and decreases protein availability in rats fed with a high-fat diet," Nutrition Research, vol. 31, 2011, pp. 157164.

[17] Y. Nakamura, A. Kaihara, K. Yoshii, Y. Tsumura, S. Ishimitsu and Y. Tonogai, "Effects of the Oral Administration of Green Tea Polyphenol and Tannic Acid on Serum and Hepatic Lipid Contents and Fecal Steroid Excretion in Rats," Journal of Health Science, vol. 47, 2001, pp. 107-111.

[18] Ikeda, R. Hamamoto, K. Uzu, K. Imaizumi, K. Nagao, T. Yanagita, Y. Suzuki, M. Kobayashi and T. Kakuda, "Dietary Gallate Esters of Tea Catechins Reduce Deposition of Visceral Fat, Hepatic Triacylglycerol and Activities of Hepatic Enzymes Related to Fatty Acid Synthesis in Rats," Bioscience Biotechnology \& Biochemistry, vol. 69, 2005, pp. 1049-1053.

[19] Tokimitsu, "Effects of tea catechins on lipid metabolism and body fat accumulation," Biofac, vol. 22, 2004, pp. 141-143.

[20] Y. Ito, T. Ichikawa, Y. Morohoshi, T. Nakamura, Y. Saegusa and K. Ishihara, "Effect of tea catechins on body fat accumulation in rats fed a normal diet," Biomedical Research, vol. 29, 2008, pp. 27-32.

[21] M. N. Woo, S. H. Bok and M. S. Choi, "Hypolipidemic and body fat -lowering effects of Fatclean in rats fed a high-fat diet," Food and Chemical Toxicology, vol. 47, 2009, pp. 2076-2082.

[22] Z. Zdunczyk, S. Frejnagel, M. Wroblewska, J. Juskiewicz, J. Oszmianski and I. Estrella, "Biological activity of polyphenol extracts from different plant sources," Food Research International, vol. 35, 2002, pp. 183-186.

[23] Lipid Research Clinics Program, "The lipid research clinics coronary primary prevention trial results: 11 . The relationship of reduction in incidence of coronary heart disease to cholesterol lowering," Journal of American Medical Association, vol. 251, 1984, pp. 365-374.

[24] G. Ramadan, N. M. El-Beih and E. A. Abd El-Ghffar, "Modulatory effects of black v. green tea aqueous extract on hyperglycaemia, hyperlipidaemia and liver dysfunction in diabetic and obese rat models," British Journal of Nutrition, vol. 102, 2009, pp. 1611-1619.

[25] P. W. F. Wilson, "High density lipoprotein, low density lipoprotein and coronary heart disease," American Journal of Cardiology, vol. 66, 1990, pp.7A-10A.

[26] R. Devi and D. K. Sharma, "Hypolipidemic effect of different extracts of Clerodendron colebrookianum Walp in normal and high-fat diet fed rats," Journal of Ethnopharmacology, vol. 90, 2004, pp. 63-68.

[27] L. De la Garza, F. I. Milagro, N. Boque, J. Campion and J. A. Martinez, "Natural inhibitors of Pancreatic Lipase as new players in obesity treatment," Planta Medica, vol. 77, 2011, pp. $773-785$.

[28] S. Uchiyama, Y. Taniguchi, B. A. Saka, A. Yoshida and H. Yajima, "Prevention of diet-induced obesity by dietary black tea polyphenols extract in vitro and in vivo," Nutrition, vol. 27, 2011, pp. 287-292.

[29] T. Murase, A. Nagasawa, J. Suzuki, T. Hase and I. Tokimitsu, "Beneficial effects of tea catechins on diet-induced obesity: stimulation of lipid catabolism in the liver," International Journal of Obesity, vol. 26, 2002, pp. 1459-1464.

[30] S. De Vos and R. De Schrijver, "Lipid metabolism, intestinal fermentation and mineral absorption in rats consuming black tea", Nutrition Research, vol. 23, 2003, pp. $527-537$.

[31] S. Nishikawa, K. Doi, H. Nakayama and K. Uetsuka, "The Effect of Fasting on Hepatic Lipid Accumulation and Transcriptional Regulation of Lipid Metabolism Differs between C57BL/6J and BALB/cA Mice Fed a High-fat Diet", Toxicologic Pathology, vol. 36, 2008, pp. 850-857.

[32] K. Kobayashi-Hattori, A. Mogi, Y. Matsumoto and T. Takita, "Effect of caffeine on the body fat and lipid metabolism of rats fed on a high-fat diet", Bioscience Biotechnology \& Biochemistry, vol. 69, 2005, pp. 2219-223.

[33] T.-F. Hsu, A. Kusumoto, K. Abe, K. Hosoda, Y. Kiso, M.-F. Wang and S. Yamamoto, "Polyphenol-enriched oolong tea increases fecal lipid excretion," European Journal of Clinical Nutrition, vol. 60, 2006, pp. 1330-1336. 